\title{
Prenatal diagnosis of a pure $15 q$ distal trisomy derived from a maternal pericentric inversion: A case report
}

\author{
FLORIN BURADA $^{1,2^{*}}$, IOANA STREATA $^{1,2^{*}}$, ANDA UNGUREANU ${ }^{3,4}$, DAN RUICAN $^{3}$, \\ RODICA NAGY ${ }^{3}$, SIMONA SERBAN-SOSOI ${ }^{1,2}$, DANAI STAMBOULI $^{5}$, LUIZA DIMOS $^{5}$, \\ GABRIELA POPESCU-HOBEANU ${ }^{1}$, IOANA MIHAI ${ }^{1,2}$ and DOMINIC ILIESCU ${ }^{3}$ \\ ${ }^{1}$ Human Genomics Laboratory, University of Medicine and Pharmacy of Craiova, 200349 Craiova; \\ ${ }^{2}$ Regional Center of Medical Genetics Dolj, Emergency Clinical County Hospital Craiova, 200642 Craiova; \\ ${ }^{3}$ Department of Obstetrics and Gynecology, University of Medicine and Pharmacy of Craiova, 200349 Craiova; \\ ${ }^{4}$ Department of Pediatric Cardiology, Emergency Clinical County Hospital Craiova, 200642 Craiova; \\ ${ }^{5}$ Cytogenomic Medical Laboratory, 014453 Bucharest, Romania
}

Received August 13, 2020; Accepted November 24, 2020

DOI: $10.3892 /$ etm.2021.9735

\begin{abstract}
Distal trisomy or duplication of $15 q$ is a very rare chromosomal disorder; most of the previously reported cases were derived from unbalanced translocations involving chromosome 15 and another chromosome, whereas other mechanisms (e.g. duplication) have rarely been reported. We herein report a very rare prenatal case of a partial $15 \mathrm{q}$ trisomy, a 42.64-Mb duplication of 15q22.2-q26.3, arising from a maternal pericentric inversion of chromosome 15 (p11q22) that was not the result of an unbalanced translocation or duplication, and was not associated with concomitant partial monosomy. Fetal ultrasound revealed isolated thickened nuchal translucency at 12 weeks and multiple abnormalities in the second trimester, including early growth restriction, unilateral ventriculomegaly, narrow cavum septi pellucidi with hypoplasia of the corpus callosum, unilateral postaxial polydactyly, clenched hands and clubfoot with clawing of the toes, and a particular general dysplastic and hypotrophic aspect of the heart. The distinctive aspects of the present case may help to refine the phenotype associated with distal duplication
\end{abstract}

Correspondence to: Dr Florin Burada, Human Genomics Laboratory, University of Medicine and Pharmacy of Craiova, Petru Rares 2, 200349 Craiova, Romania

E-mail: buradaflorin@gmail.com

Dr Anda Ungureanu, Department of Pediatric Cardiology, Emergency Clinical County Hospital Craiova, Tabaci 1, 200642 Craiova, Romania E-mail: ungureanu_anda@yahoo.com

*Contributed equally

Key words: prenatal diagnosis, partial trisomy, 15q duplication, inversion, array $\mathrm{CGH}$, karyotype 15q. To the best of our knowledge, this is the first report of a prenatal diagnosis with a $15 \mathrm{q} 22.2-\mathrm{q} 26.3$ duplication that did not result from an unbalanced translocation and did not have a concomitant monosomic component.

\section{Introduction}

Distal trisomy or duplication of $15 q$ is a very rare chromosomal disorder in which three copies of distal part of the long arm of chromosome 15 are found in cells. Following the first report by Fujimoto et al (1), more than 80 cases were published, but only a few were diagnosed prenatally. Most of the reported cases were mainly derived from unbalanced translocations involving chromosome 15 and another chromosome (2), whereas other mechanisms (e.g. duplication) were rarely found (3-5). In most cases, a concomitant genetic abnormality (e.g. partial monosomy) was present and thus the phenotype could have been influenced. A large variability of clinical features has been documented, depending on the size of the duplicated $15 q$ fragment. However, there are consistent and recognizable clinical phenotypes presenting a partial duplication of distal $15 q$, which are characterized by minor craniofacial anomalies, mental retardation, finger defects, congenital heart disease, and urogenital abnormalities (6).

We herein report a very rare prenatal case with a partial $15 \mathrm{q}$ trisomy arising from a pericentric inversion of chromosome 15 that was not the result of an unbalanced translocation or duplication and did not have a concomitant partial monosomy. In addition, a $5 q$ paracentric inversion was present. Both chromosomal abnormalities were of maternal origin.

\section{Case report}

A 35-year-old, primigravida woman was referred to our center for first trimester anomaly and genetic scan, with a negative history of congenital abnormalities. An isolated thickened nuchal translucency at 12 weeks of gestation $(5.87 \mathrm{~mm})$, was observed on the detailed first-trimester ultrasound anomaly 

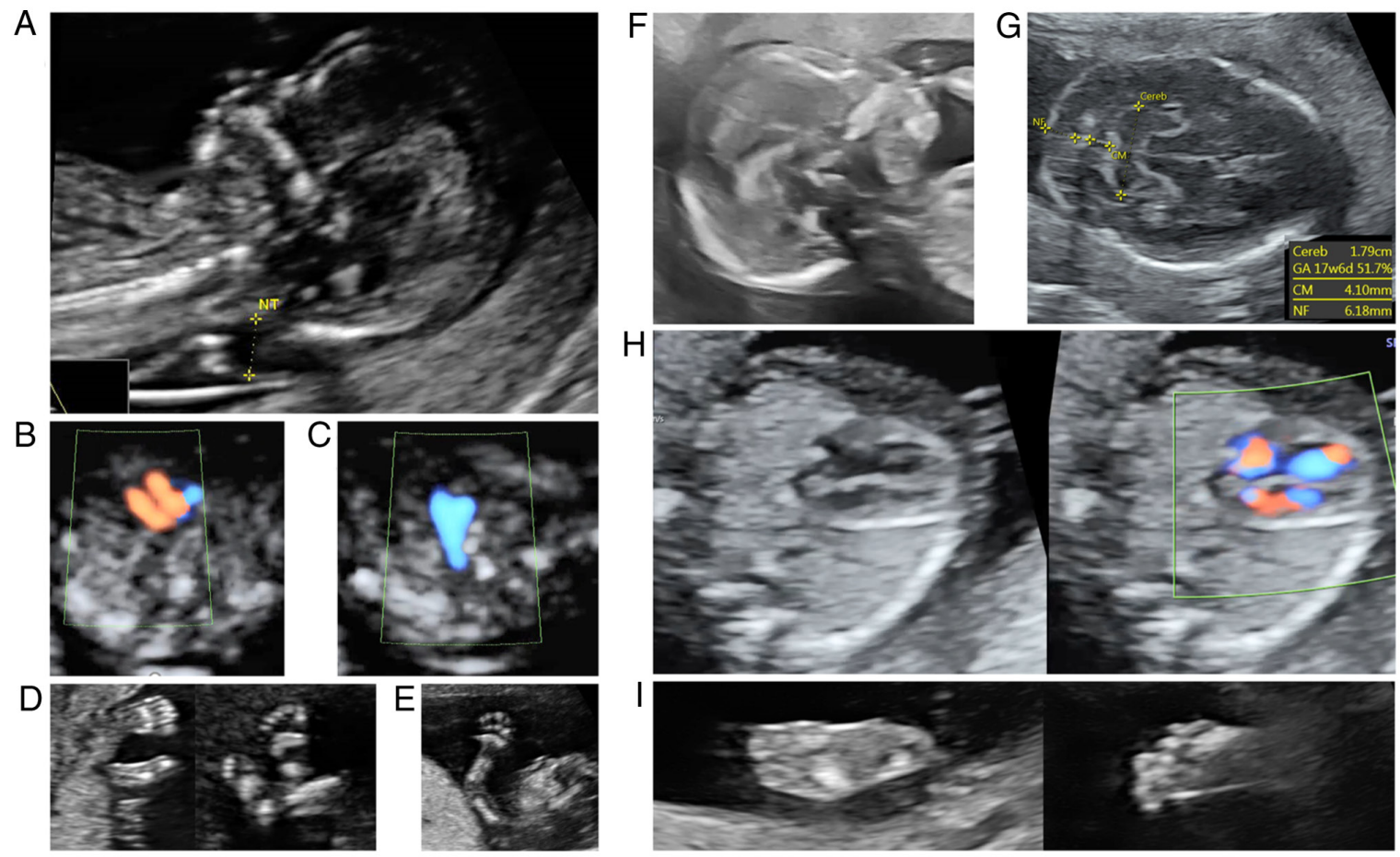

Figure 1. Early anomaly scan. (A) Isolated thickened nuchal translucency at 12 weeks of gestation with (B and C) normal appearance of the cardiac features: (B) atrio-ventricular flows and (C) arterial arches confluence, three-vessel view, and normal limb aspects: (D) feet and (E) hand. Four weeks later, early morphological fetal evaluation at 16 gestational weeks revealed: $(F$ and $G)$ increased nuchal fold in sagittal and axial planes of the fetal head, $(H)$ narrow appearance of the cardiac chambers, and (I) abnormal toe aspect.
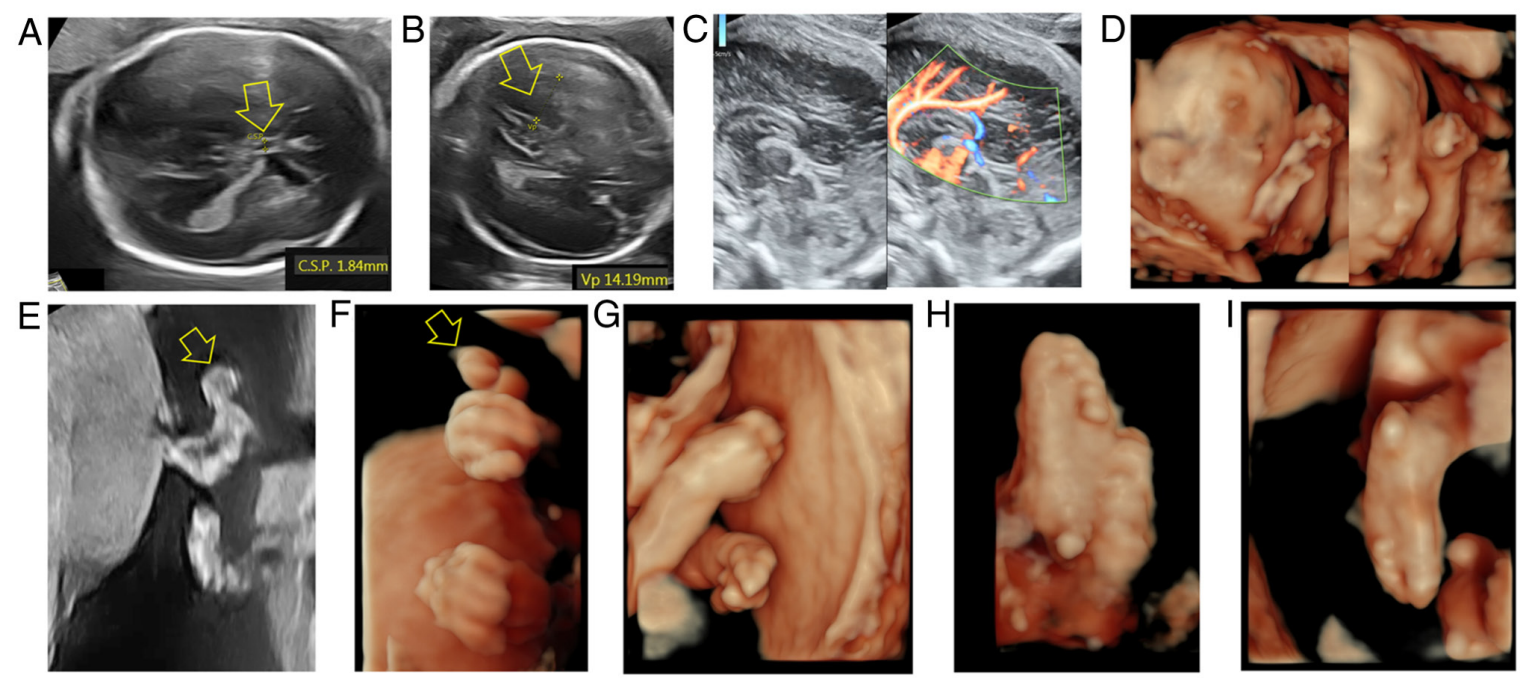

Figure 2. Fetal central nervous system and limbs at 22 gestational weeks. (A, open arrow) Narrow cavum septi pellucidi, (B, open arrow) unilateral ventriculomegaly, (C) hypoplasia of the corpus callosum, evident in duplex gray-scale and power Doppler mode, that highlights pericallosal artery, and (D) facial profile with low-set ears and long philtrum. (E and F) Skeletal abnormalities included postaxial polydactyly indicated with arrow in 2D and 3D rendering. (G) Clenched hands and ( $\mathrm{H}$ and $\mathrm{I}$ ) clubfoot with bilateral clawing of the toes.

scan, accompanied by normal cardio-vascular findings (Fig. 1). Serial fetal scans between 18-22 weeks revealed an early growth restriction, along with multiple and complex anomalies, difficult to interpret. Fetal neurosonography detected unilateral ventriculomegaly, narrow cavum septi pellucidi with hypoplasia of the corpus callosum, increased nuchal fold, and minor facial abnormalities-low-set ears (Fig. 2). Skeletal abnormalities were detected in the second trimester: Unilateral postaxial polydactyly, clenched hands and clubfoot with clawing of the toes (Fig. 2). Cardio-vascular ultrasound assessment yielded unspecific abnormalities at the second trimester anomaly scan: Narrow appearance of the cardiac chambers (Fig. 3), disproportion between the right and left heart, with wider right ventricle and pulmonary artery, dysplastic atrioventricular valves with 'de novo' tricuspid regurgitation, sinus venosus, atrial septal defect and several ventricular muscular septal defects.

The pregnancy was terminated at 24 weeks, following multidisciplinary counselling that involved geneticists and 

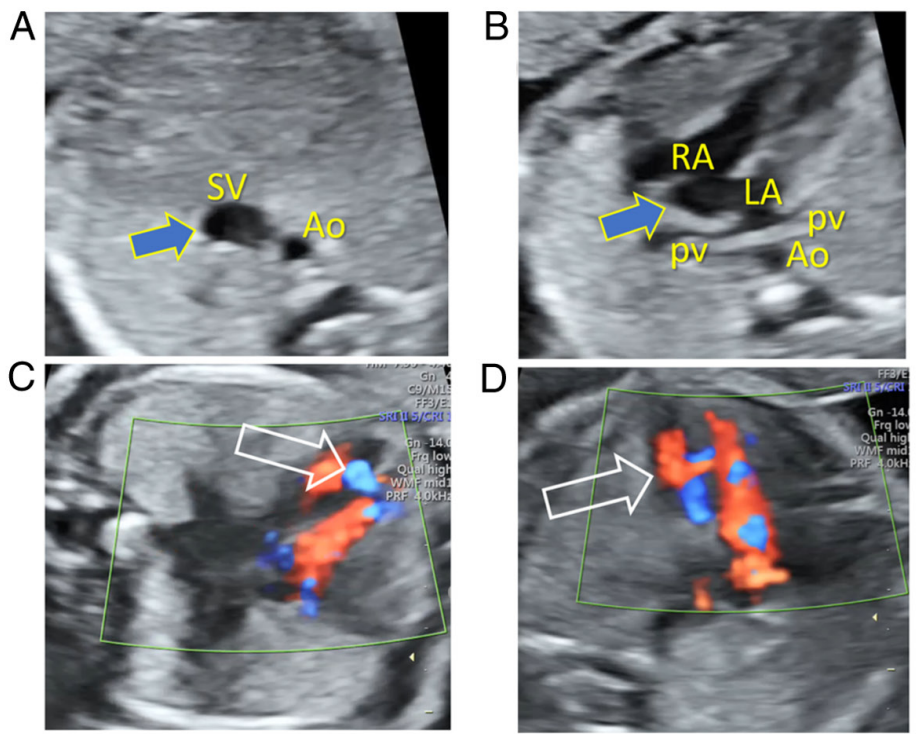

$\mathrm{D}$

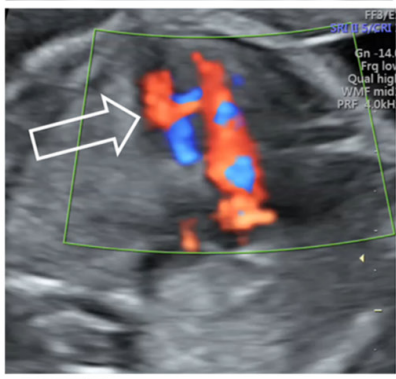

$\mathrm{E}$
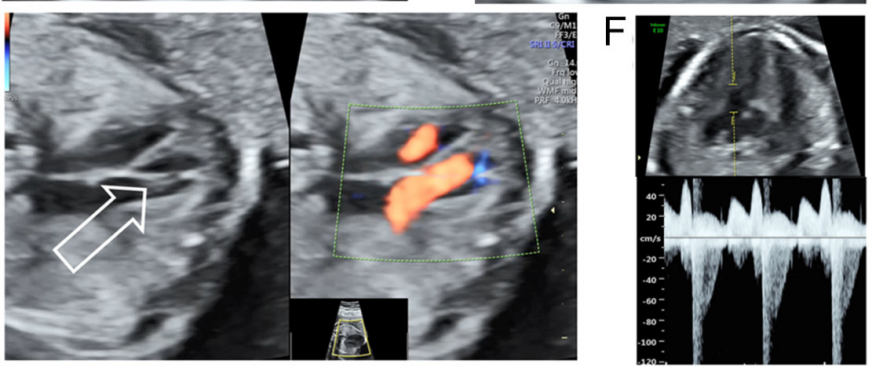

G

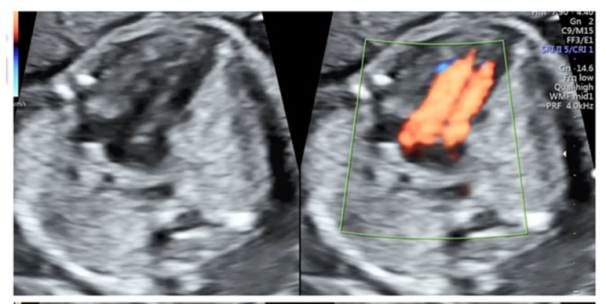

$\mathrm{H}$
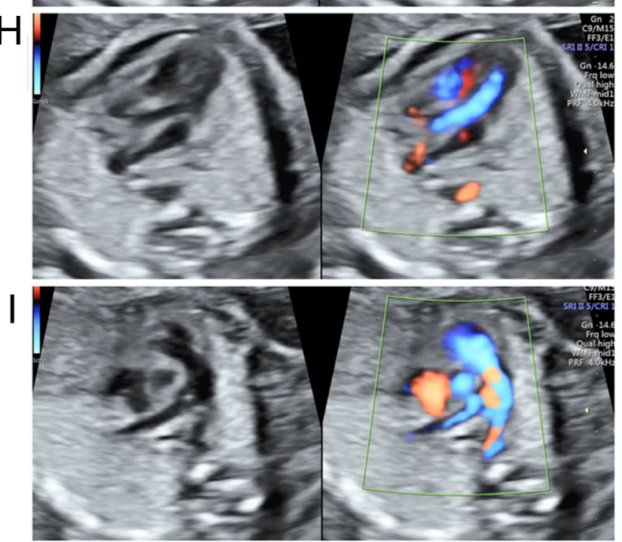

J

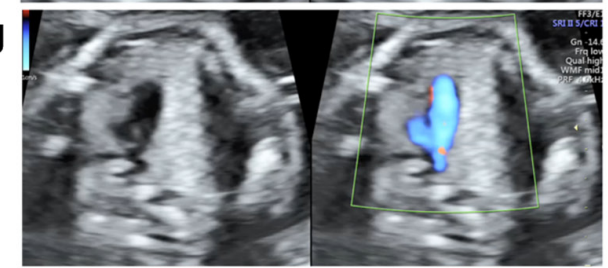

Figure 3. Heart abnormalities at the second trimester anomaly scan. (A and B) Sinus venosus atrial septal defect, with an enlarged sinus venosus (arrow), visible under the diaphragm in the axial abdominal plane, then communicating with both atria in the axial thoracic plane just above the diaphragm, and draining predominantly in the left atrium. (C and D) Several ventricular muscular septal defects were identified near the cardiac apex with color Doppler mode (arrows). (E) Narrow cardiac chambers and dysplastic appearance of atrioventricular valves at the four-chamber plane using concomitant grey-scale and high definition power Doppler. Narrow mitral annulus with little mobility of the mitral valve leaflets, accompanied by a left atrioventricular flow almost half of the right atrio-ventricular flow width. Downward displaced tricuspid valve leaflets (arrow), tethered at the muscular ventricle septum with right ventricular atrialization and a small effective right ventricular cavity. (F) Tricuspid valve interrogation with pulsed Doppler, showing 'de novo' tricuspid regurgitation at 22 gestational weeks. (G-J) Cardiac sweep, in duplex grey-scale and high definition directional power Doppler modes, showing: (G) narrow cardiac chambers in four-chamber view and (H and I) antegrade ventricular outflows and (J) normal course of the aorta and arterial ductus. Mild disproportion between the right and left heart, with (G) wider right ventricle and (I) pulmonary artery. Ao, aorta; SV, sinus venosus; pv, pulmonary veins; LA, left atrium; RA, right atrium; IVC, inferior vena cava.

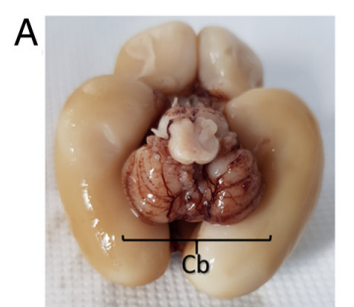

B

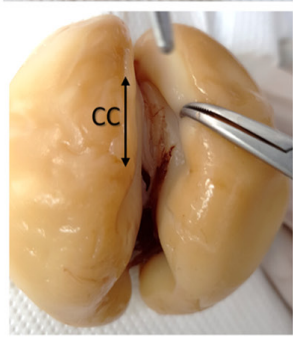

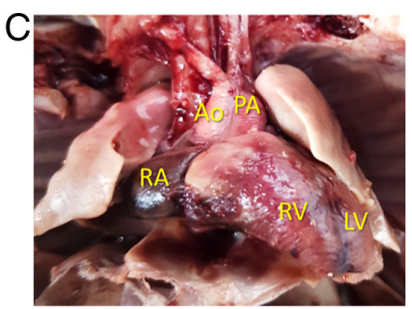

$\mathrm{F}$

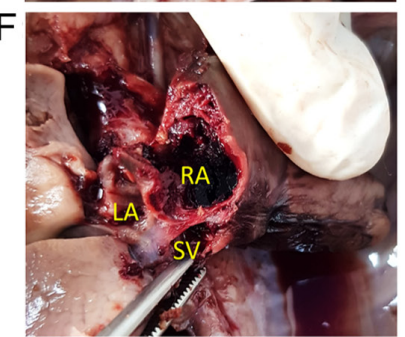

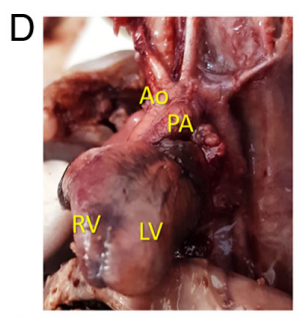

G

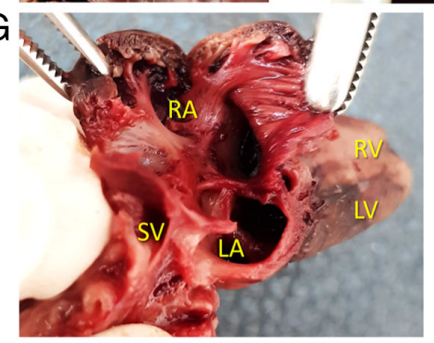

$\mathrm{E}$
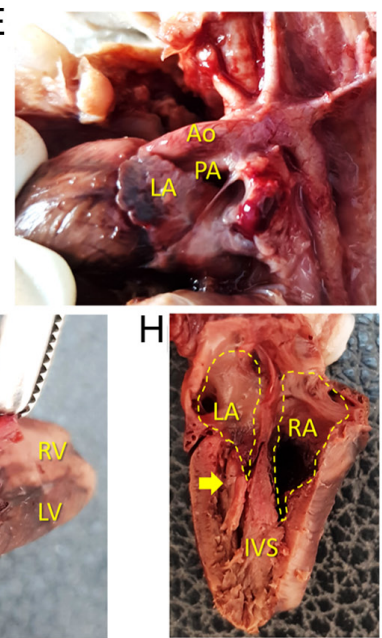

Figure 4. Fetal autopsy following pregnancy termination at 24 gestational weeks. (A and B) Brain evaluation revealed: (A) a normal general aspect of the hemispheres and cerebellum, and (arrows, B) a small corpus callosum. (C-H) Heart and great vessel evaluations showed: (C and D) a general hypotrophic aspect, and (C-E) a normal course of the arterial arches (C-E) (F and G) A large venous sinus (star) was found at the base of the heart communicating with both atria. (F and G) The right atrium, enlarged and thickened, was sectioned for a better view of the veno-atrial connections. The coronal view of the fetal heart was useful for evidencing the atrialization of the right ventricle, the thickened appearance of the mitral valve (arrow), and the irregular shape of the interventricular septum, suggesting multiple ventricular septal defects. Cb, cerebellum; CC, corpus callosum; RA, right atrium; LA, left atrium; RV, right ventricle; LV, left ventricle; SV, sinus venosus; PA, pulmonary artery; Ao, aorta; IVS, interventricular septum. 
A

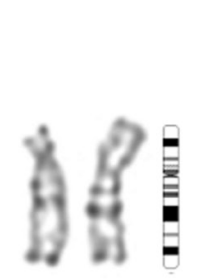

15

C

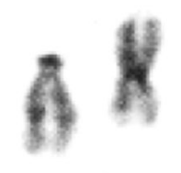

B

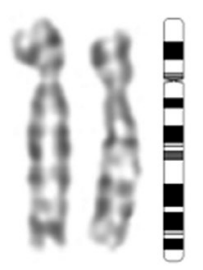

5

D

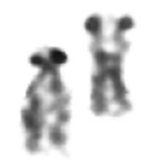

15

Figure 5. Partial karyotypes. (A) Fetus (amniotic fluid sample): The recombinant chromosome 15 and the 5q paracentric inversion-GTG banding. (B) Mother (peripheral blood): The paracentric inversion of chromosome 15 and the $5 \mathrm{q}$ paracentric inversion-GTG banding. (C) Mother (peripheral blood): The paracentric inversion of chromosome 15-CBG banding. (D) Mother (peripheral blood): The paracentric inversion of chromosome 15-NOR banding.

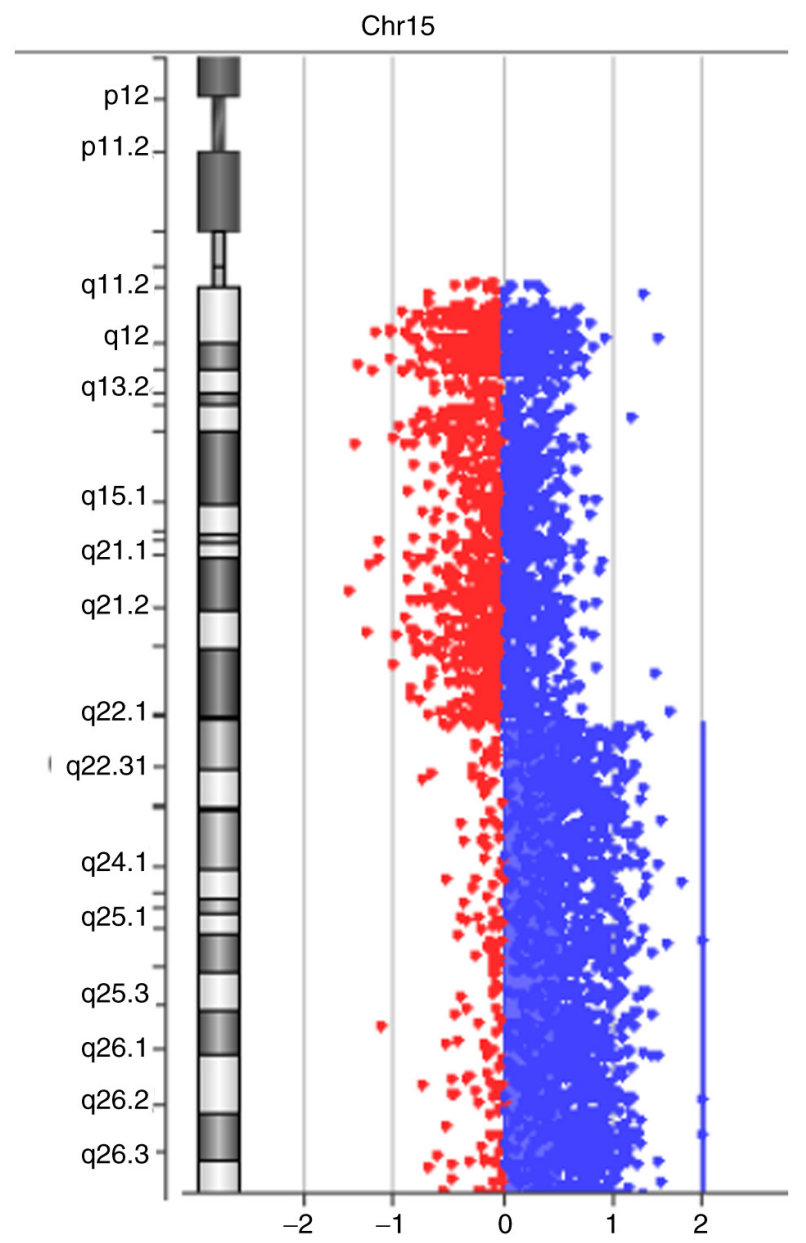

Figure 6. Array CGH analysis of fetal DNA extracted from amniotic fluid showing a 42.64-Mb duplication in the region 15q22.2-q26.3. Image generated with Agilent Cytogenomics 5.0 software (Agilent Technologies, Inc.).

maternal-fetal specialists, and the fetal autopsy confirmed the prenatal ultrasound findings (Fig. 4).

The diagnostic amniocentesis was performed at week 18. Standard chromosome analysis by GTG banding was performed on metaphases prepared from amniotic cell culture.
The cytogenetic analysis showed additional chromosomal material on the short arm of one chromosome 15 and a $5 q$ paracentric inversion in all examined cells. In order to determine the parental origin of abnormalities (de novo or familial rearrangements), chromosome analysis was also performed on the peripheral blood of both parents using GTG banding. The conventional cytogenetic analysis from the peripheral blood revealed a normal paternal karyotype of 46,XY, and an abnormal maternal karyotype with two inversions 46,XX,inv(5) (q15q33),inv(15)(p11q22). In addition, NOR and CBG banding were used to characterize the inv (15) in the mother. According to ISCN 2016 (7), the fetal karyotype was designated as $46, X X, \operatorname{inv}(5)(q 15 q 33), \operatorname{rec}(15)(q t e r \rightarrow q 22.2:: p 11.1 \rightarrow$ qter)mat.

The chromosomal abnormalities involving chromosomes 5 and 15 of both fetus and mother are shown in Fig. 5, alongside the ideograms generated by CyDAS software (8).

Genomic DNA was extracted from amniotic fluid, according to previously described methods (9). Quantitative fluorescence-PCR analysis was performed on the DNA extracted from uncultured amniocytes and parental peripheral blood samples. Devyser Extend kit with genetic markers for aneuploidy analysis of chromosomes $13,15,16,18,21,22, \mathrm{X}$ and $\mathrm{Y}$ was used to exclude the most common aneuploidies and uniparental disomy of chromosome 15.

Array CGH analysis of the DNA extracted from amniotic fluid using SurePrint CGH ISCA v2, 8x60 K Array (Agilent Technologies, Inc.) revealed a 42.64-Mb duplication of 15q22.2-q26.3 (Fig. 6) or $\operatorname{arr}[$ GRCh37] 15q22.2q26.3 (59824654-102465355) x3 (ISCN 2016), encompassing 455 genes including 209 Online Mendelian Inheritance in Man (OMIM) genes. Prenatal array revealed no further significant imbalances in other chromosomes or in the maternally inherited breakpoint regions, that might also have an influence on the phenotype. Array CGH analysis confirmed that the additional fragment on chromosome 15 is a $15 \mathrm{q}$ fragment derived from the unbalanced pericentric inversion 15 (p11q22). Agilent Cytogenomics 5.0 software was used to analyze copy number data.

\section{Discussion}

To our knowledge, this is the first report of a partial trisomy $15 q$ arising from a pericentric inversion. Unbalanced gametes 
may arise from a pericentric inversion as a result of the formation of recombinant chromosomes. A recombinant chromosome resulting from a pericentric inversions involving an acrocentric chromosome leads to either a partial trisomy or a partial monosomy of the long arm, due to the fact that the gain or loss of genetic material of the short arm is without phenotypic consequences.

Most cases with partial trisomy of a segment of distal $15 q$ were the result of unbalanced translocations or a duplication in a small number of cases, such that deletions of other chromosomes were commonly seen with $15 \mathrm{q}$ duplication $(10,11)$. Thus, it is difficult to establish which clinical features can be specifically attributed to the $15 \mathrm{q}$ trisomy or to the other chromosomal monosomy.

The spectrum of clinical findings vary from case to case, depending upon the length and location of the duplicated portion of chromosome 15q (3). The previously duplicated regions range from 15q23.1-qter to 15q26.1-qter (6). In our case the array $\mathrm{CGH}$ analysis demonstrated the duplicated $15 \mathrm{q}$ segment spans $15 q 22.2$-qter. There is only a few data available on the prenatal features of duplication $15 \mathrm{q}$, whereas postnatal phenotypic findings in distal duplication $15 \mathrm{q}$ syndrome are variable and characterized by prenatal and postnatal overgrowth, facial dysmorphism (abnormal palpebral fissures, large prominent nose, facial asymmetry, ptosis, and micrognathia), severe mental deficiency, congenital heart disease, hand defects, or urogenital anomalies. In our case, fetal ultrasound evaluation revealed growth restriction, mild facial dysmorphic features (only low-set ears), distal extremity skeletal, central nervous system abnormalities (CNS) that may be linked to the previous mental retardation observed, and unspecific heart anomalies, difficult to interpret, as a general cardiac hypoplasia was not previously described.

Partial hypoplasia of corpus callosum, high-grade intraventricular hemorrhage, and parietal periventricular hyperechogenic brain parenchyma, anencephaly and neural tube defects were noted in 15q duplication (12-14). Dysmorphic facies with long philtrum, up-slanting palpebral fissures, bulbous nasal tip or bifid uvula, high frontal hairline, ptosis, down-slanting palpebral fissures, broad nasal bridge, long philtrum, and high-arched palate have been described in postnatal patients $(6,10)$. All these features are difficult to ascertain prenatally by early second-trimester ultrasound scan. However, we did suspect some of these phenotypic aspects during the ultrasound examinations and the autopsy following pregnancy termination. A wide variety of cardiac defects, including atrial and ventricular septal defects, patent ductus arteriosus, and anomalies of the tricuspid valve were commonly seen $(3,15,16)$, and some of them also present in our case. However, the heart abnormalities detected in our case were more severe. Moreover, finger and toe abnormalities (camptodactily, arachnodactyly, overlapping of the second and third toes, shortened thumb, broad first toe) were observed as well $(3,15)$.

The duplicated chromosomal fragment encompasses 209 OMIM genes. Of particular interest, is insulin-like growth factor 1 receptor (IGF1R) gene located on $15 q 26.3$, which is involved in pre- and postnatal growth. The alterations of IGF1R expression and function were considered to cause somatic overgrowth $(3,6)$, but recent reports of postnatal and prenatal cases with $15 \mathrm{q}$ duplication, revealed that $I G F 1 R$ triplication is also associated with intrauterine growth restriction (IUGR) and failure to thrive and short stature (14,16-19). In our case, fetal ultrasound assessment identified growth restriction instead of overgrowth. Our findings sustain the theory that the growth phenotype is not a single gene encoded trait, thus being the result of global transcription dysregulation or hidden mosaicism (17). Also, several studies reported that the protein encoded by IGFRI gene plays an important role in processes like neuronal cell survival and synaptic maturation, essential for achieving normal development of CNS $(17,20)$. In our case, CNS anomalies such as unilateral ventriculomegaly, and narrow cavum septi pellucidi with hypoplasia of the corpus callosum were detected by neurosonography, supporting the idea that IGFR-1 signaling is involved in CNS development. The affected region contains also other genes reported to be involved in brain development and functioning: $C H D 2, K I F 7$, LINGO1, AP3B2, HOMER2, SH3GL3 or NMB.

Furthermore, fetal ultrasound evaluation revealed in our case multiple anomalies of the face and distal skeleton, as well as unspecific anomalies of the heart. The duplicated region identified through array $\mathrm{CGH}$ testing contains several genes that could be involved in the etiology of these abnormal findings. Thus, CHSY1, EFL1 or CILP gene duplications, might explain anomalies such as unilateral postaxial polydactyly, clenched hands and clubfoot with clawing of the toes that were identified in our case. CHSY1 mutations are causing temtamy preaxial brachydactyly syndrome, characterized by reduced body length and severe midline deficiencies in the cartilage of the neurocranium (21). Unspecific cardiac anomalies such as narrow appearance of the cardiac chambers, dysplastic atrioventricular valves with 'de novo' tricuspid regurgitation, atrial septal defect and several ventricular muscular septal defects might be the result of an alteration in SMAD6, SMAD3, MEF2A or MTHFS gene expression and function (12,17,22-27). These unreported ultrasound findings (heart and hands abnormalities) can be explained by the size and position of duplicated $15 \mathrm{q}$ region.

Our study has some limitations. First, the lack of FISH analysis with specific probes to the ribosomal genes limited a more complex delineation of rearrangements involving chromosome 15 . This was attenuated by the size of the duplicated fragment and the use of other standard and molecular cytogenetic methods. Moreover, we were not able to provide a reliable recurrence risk estimation, because the chromosomal analysis of the grandparents and other family members was not possible.

In conclusion, this is the first report of a prenatal diagnosis with a 15q22.2-q26.3 duplication that did not result from an unbalanced translocation and did not have a concomitant monosomic component. The rarity of this genetic syndrome was accompanied in our case by an equally rare ultrasound prenatal abnormal appearance, with a more severe presentation of the malformative features, a particular general dysplastic and hypotrophic aspect of the heart and fetal growth restriction. These distinctive aspects of our case can help refine the phenotype associated with distal duplication $15 q$.

\section{Acknowledgements}

Not applicable. 


\section{Funding}

No funding was received.

\section{Availability of data and materials}

The datasets used and/or analyzed during the current study are available from the corresponding author on reasonable request.

\section{Authors' contributions}

FB, IS and DI conceived the present study, performed the literature research and wrote the draft of the manuscript. FB, SSS and GPH performed the standard cytogenetic analysis and interpreted the karyotypes. DS and LD performed the NOR and CBG banding and interpreted the results. IS, SSS and $\mathrm{MI}$ performed the array $\mathrm{CGH}$ analysis and interpreted the cytogenomic data. DI, RN, DR and AU performed the fetal ultrasound examinations and the fetal autopsy, obtained the biological samples and clinical data. GPH provided professional editing, linguistic and technical assistance, certified translator. All authors read and approved the final manuscript.

\section{Ethics approval and consent to participate}

The present study followed the international and national regulations in accordance with the Declaration of Helsinki.

\section{Patients consent for publication}

Written informed consent for publication of the data/images associated with the manuscript was obtained from parents prior to the study. The authors followed the international and national regulations in accordance with the Declaration of Helsinki and all identifying information was removed.

\section{Competing interests}

The authors declare that they have no competing interests.

\section{References}

1. Fujimoto A, Towner JW, Ebbin AJ, Kahlstrom EJ and Wilson MG: Inherited partial duplication of chromosome No. 15. J Med Genet 11: 287-291, 1974.

2. Rowe AG, Abrams L, Qu Y, Chen E and Cotter PD: Tetrasomy 15q25->qter: Cytogenetic and molecular characterization of an analphoid supernumerary marker chromosome. Am J Med Genet 93: 393-398, 2000

3. Kim EY, Kim YK, Kim MK, Jung JM, Jeon GW, Kim HR and Sin JB: A case of de novo duplication of 15q24-q26.3. Korean J Pediatr 54: 267-271, 2011.

4. Chandler K, Schrander-Stumpel CT, Engelen J, Theunissen P and Fryns JP: Partial trisomy 15q: Report of a patient and literature review. Genet Couns 8: 91-97, 1997.

5. Elçioglu N, Fear C and Berry AC: Partial trisomy of $15 \mathrm{q}$ due to inserted inverted duplication. Clin Genet 52: 442-445, 1997.

6. Tatton-Brown K, Pilz DT, Orstavik KH, Patton M, Barber JCK, Collinson MN, Maloney VK, Huang S, Crolla JA, Marks K, et al: $15 \mathrm{q}$ overgrowth syndrome: A newly recognized phenotype associated with overgrowth, learning difficulties, characteristic facial appearance, renal anomalies and increased dosage of distal chromosome 15q. Am J Med Genet A 149A: 147-154, 2009.

7. McGowan-Jordan J, Simons A, Schmid M (eds.): An international system for human cytogenomic nomenclature (2016). S. Karger, Basel. Reprint of Cytogenet Genome Res 149, 2016.
8. Hiller B, Bradtke J, Balz H and Rieder H: CyDAS: A cytogenetic data analysis system. BioInformatics 21: 1282-1283, 2005.

9. Sosoi S, Streata I, Tudorache S, Burada F, Siminel M, Cernea N, Ioana M, Iliescu DG and Mixich F: Prenatal and postnatal findings in a $10.6 \mathrm{Mb}$ interstitial deletion at $10 \mathrm{p} 11.22-\mathrm{p} 12.31$. J Hum Genet 60: 183-185, 2015.

10. Puvabanditsin S, Khan I, Garrow E, Botti C, Lambert G and Quan M: Partial trisomy $15 \mathrm{q} 23$ and partial monosomy 5p15.32: Case report and a literature review. Am J Med Genet A 161A: 3201-3204, 2013.

11. El-Bassyouni HT, El-Gerzawy AM, Mohamed AM, Kamel AK, Hussein HA, Thomas MM and El-Ruby M: Terminal 2q deletion and partial trisomy chromosome 15q: A clinical and cytogenetic study. Genet Couns 25: 151-158, 2014.

12. Chen CP, Chen CY, Chern SR, Wu PS, Chen SW, Lai ST, Lee CC, Yang CW and Wang W: Molecular cytogenetic characterization of a duplication of 15q24.2-q26.2 associated with anencephaly and neural tube defect. Taiwan J Obstet Gynecol 56: 550-553, 2017.

13. Abe Y, Tanaka D, Soga T, Takeuchi T and Iikura Y: A case of de novo distal duplication of chromosome 15. Clin Genet 63: 76-78, 2003.

14. Roggenbuck JA, Mendelsohn NJ, Tenenholz B, Ladda RL and Fink JM: Duplication of the distal long arm of chromosome 15: Report of three new patients and review of the literature. Am J Med Genet A 126A: 398-402, 2004.

15. McLaughlin BM, Hufnagel RB and Saal HM: Small bowel malrotation in distal $15 \mathrm{q}$ duplication: Evidence for a rare association. Clin Dysmorphol 24: 65-67, 2015.

16. Miller MS, Rao PN, Dudovitz RN and Falk RE: Ebstein anomaly and duplication of the distal arm of chromosome 15: Report of two patients. Am J Med Genet A 139A: 141-145, 2005.

17. Cannarella R, Mattina T, Condorelli RA, Mongioì LM, Pandini G, La Vignera S and Calogero AE: Chromosome 15 structural abnormalities: Effect on IGF1R gene expression and function. Endocr Connect 6: 528-539, 2017.

18. Luo M, Mulchandani S, Dubbs HA, Swarr D, Pyle L, Zackai EH, Spinner NB and Conlin LK: Detection of mutually exclusive mosaicism in a girl with genotype-phenotype discrepancies. Am J Med Genet A 167A: 3091-3095, 2015.

19. Schinzel A: A Catalog of Unbalanced Chromosome Aberration in Man. 2nd edition. De Gruyter Verlag, Berlin, 2001.

20. Tropea D, Giacometti E, Wilson NR, Beard C, McCurry C, Fu DD, Flannery R, Jaenisch R and Sur M: Partial reversal of Rett Syndrome-like symptoms in MeCP2 mutant mice. Proc Natl Acad Sci USA 106: 2029-2034, 2009.

21. Li Y, Laue K, Temtamy S, Aglan M, Kotan LD, Yigit G, Canan H, Pawlik B, Nürnberg G, Wakeling EL, et al: Temtamy preaxial brachydactyly syndrome is caused by loss-of-function mutations in chondroitin synthase 1, a potential target of BMP signaling. Am J Hum Genet 87: 757-767, 2010.

22. Kloth K, Bierhals T, Johannsen J, Harms FL, Juusola J, Johnson MC, Grange DK and Kutsche K: Biallelic variants in SMAD6 are associated with a complex cardiovascular phenotype. Hum Genet 138: 625-634, 2019.

23. Gillis E, Kumar AA, Luyckx I, Preuss C, Cannaerts E, van de Beek G, Wieschendorf B, Alaerts M, Bolar N, Vandeweyer G, et al: Candidate gene resequencing in a large bicuspid aortic valve-associated thoracic aortic aneurysm cohort: SMAD6 as an important contributor. Front Physiol 8: 400, 2017.

24. Hostetler EM, Regalado ES, Guo DC, Hanna N, Arnaud P, Muiño-Mosquera L, Callewaert BL, Lee K, Leal SM, Wallace SE, et al: SMAD3 pathogenic variants: Risk for thoracic aortic disease and associated complications from the montalcino aortic consortium. J Med Genet 56: 252-260, 2019.

25. Xu H, Xiao B, Ji X, Hu Q, Chen Y and Qiu W: Nonmosaic tetrasomy $15 q 25.2 \rightarrow$ qter identified with SNP microarray in a patient with characteristic facial appearance and review of the literature. Eur J Med Genet 57: 329-333, 2014.

26. George-Abraham JK, Zimmerman SL, Hinton RB, Marino BS, Witte DP and Hopkin RJ: Tetrasomy 15q25.2 $\rightarrow$ qter identified with SNP microarray in a patient with multiple anomalies including complex cardiovascular malformation. Am J Med Genet A 158A: 1971-1976, 2012.

27. Hall NG, Klenotic P, Anand-Apte B and Apte SS: ADAMTSL-3/punctin-2, a novel glycoprotein in extracellular matrix related to the ADAMTS family of metalloproteases. Matrix Biol 22: 501-510, 2003.

This work is licensed under a Creative Commons Attribution-NonCommercial-NoDerivatives 4.0 International (CC BY-NC-ND 4.0) License. 